\title{
Study of condensation at the surfaces of tube with gradient heat flux measurement
}

\author{
Sergey Sapozhnikov ${ }^{1}$, Vladimir Mityakov ${ }^{1}$, Alexandr Babich $^{1, *}$, and Elza Zainullina ${ }^{1}$ \\ ${ }^{1}$ Peter the Great St. Petersburg Polytechnic University, 195251, 29 Politekhnicheskaya st., Saint \\ Petersburg, Russia
}

\begin{abstract}
Gradient heat flux measurement is used for study of heat transfer during condensation of water steam at inner and outer surfaces of tube. Experimental setups allow producing experiments with minimal distortion of condensate film flow. Experiments were carried out for different directions of steam and cooling water flows and for different angles of tube inclination relative to the vertical. Heat transfer coefficients and their change along the length and perimeter of tube were measured. The obtained data allow to study formation of condensate film and parameters of film motion. The results are corresponding to classical ideas.
\end{abstract}

\section{Introduction}

Information about heat transfer during condensation is necessary for calculation of heat exchangers for nuclear and heat power plants.

In this paper the results from two different setups are shown. One of them is about condensation at the inner surface, and another one is about condensation at the outer surface of pipe.

Nusselt has put forward his model of condensation more than 100 years ago but today almost all equations are based at it [1]. This model is not ideal because he introduced several assumptions. Nusselt equation is valid for stationary steam flow, but there are the waves of condsnsate film thickness which improve condensation heat transfer coefficient (HTC).

HTC equations for condensation inside vertical tubes are based on Nusselt formula with the correlation factor equal to 1.2. In 1948 Kapitsa showed that HTC is $20 \%$ higher than Nusselt predicted [2]. Later Kapitsa wrote that HTC depend on Reynolds and Kapitsa numbers [3]. In 1957 Labuntsov proposed correlation in the form of dependence of Nusselt number from Reynolds number, because Kapitsa numbers do not much effect on HTC [4]. Nozhat studied the effect of surface tension and curvature of the surface and gave his correlation number [5].

First experiments about condensation inside vertical tubes were published in 1935 by Icob [6]. Today there is a lot of experiments about condensation inside tubes due to Fukushima Daiichi nuclear disaster. Many scientists are working on improving the safety of nuclear power plants. Korean researchers determined the local HTC during condensation with presence and absence of noncondensable gases [7]. Japanese authors investigated counterflow of steam and condensate in U-shaped tubes [8]. Also, in Russia experiments about condensation inside large diameter tubes were provided [9].

HTC equations for condensation at the outer surface of vertical tube are also based on Nusselt formula [1]. The influence of fluid properties was studied byVoskresensky and Labuntsov [10], who introduced the correction to variability of fluid properties.

\footnotetext{
* Corresponding author: babich1994@mail.ru
} 
We also study condensation at the outer surface of vertical, horizontal and inclined tubes. Nusselt formula was done for the condensate film thickness at the surface of horizontal tube [1].The first analytical solution for inclined surface we have found is presented in the work of Hassan and Jacob [11]. They considered the laminar flow of condensate film under the action of gravity at the outer surface of inclined tube. Kamming reconsidered Hassan and Jakob equation and gave the solution of the partial differential equation for film thickness [12]. Comparison with the experimental data was not available due to the solution complexity.produced in this sphere. Air - steam condensation at the outer surface of vertical tube were studied by Korean scientists [13], who visualizated the process. Zhang and Wang studied air accumulation in vapor condensation in horizontal tube. They measure heat flux along the tube perimeter [14].

Our group offers unique approach for study of heat transfer during the condensation gradient heat flux measurement, which is based on using of gradient heat flux sensors (GHFS) [15]. GHFS has already used in the diesel engine [16,17], convection study [18,19] and during condensation [20].

\section{Method}

\subsection{Gradient heat flux sensors}

The operation principle of GHFS is based on transverse Seebeck effect, which comes out of the anisotropy of thermal and electrophysical properties of matter (figure 1)/

The GHFS's indications are proportional to heat flux per unit area:

$$
E=S_{0} \cdot F \cdot q
$$

Here, $E$ is the electromotive force, $S_{0}$ is the GHFS sensitivity, $F$ is GHFS area, $q$ is heat flux per unit area.

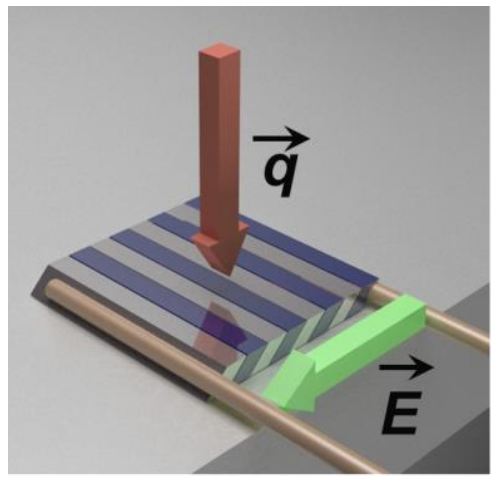

a)

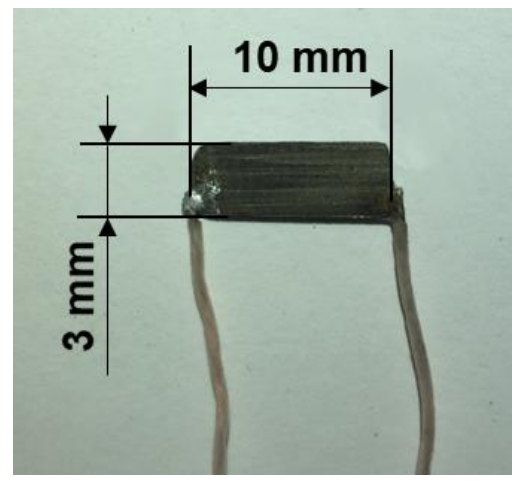

b)

Fig. 1. GHFS schematic representation (a) and photo (b).

Heterogeneous gradient heat flux sensors (HGHFS) of steel+nickel composite were used. Their time constant was of $10^{-8} \ldots 10^{-9} \mathrm{~s}$. Individual calibration of all sensors by absolute method was carried out.

\subsection{Condensation at the inner surface of the tube}


The main task in the experimental setup design was to reduce distortion of condensate film flow. Four segments (figure 2, a, b) along the length of the tube were cut off by an electrospark machine and then installed back flush with the inner surface of the tube.

The tube with installed segments was placed in a plastic cover and fastened by two rubber plugs. All wires were removed through the upper rubber plug that ensured tightness of the installation. Overall view of the experimental setup is shown at figure 2, c.

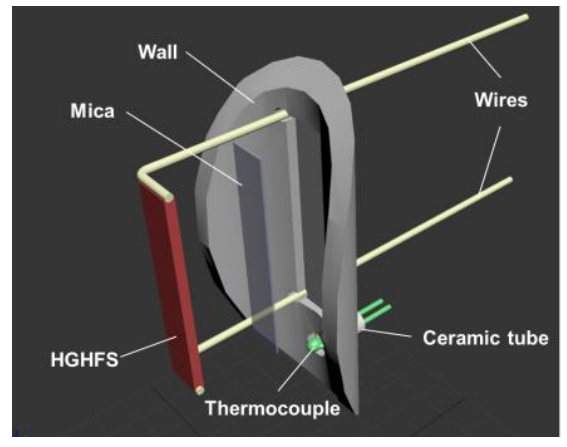

a)

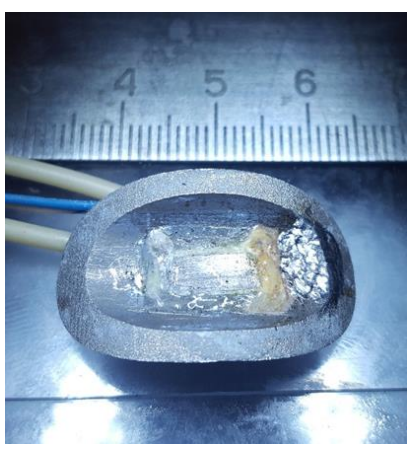

b)

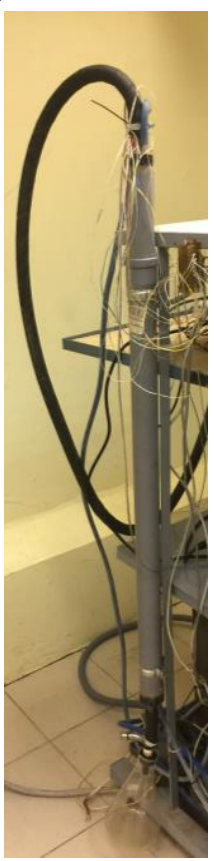

c)

Fig.2. Photo of the (a) segment, the segment soldered to the tube (b), the overall view of the experimental setup(c).

Steam with a pressure close to atmospheric and temperature about $100{ }^{\circ} \mathrm{C}$ was fed from the steam generator with power of $12 \mathrm{~kW}$ into the steel tube from the top or from the bottom. The cooling water was fed into the annular distance between the tube and the cover from the bottom.

\subsection{Condensation at the outside surface of the tube}

The experimental setup consists of two coaxially arranged tubes (figure 3 ). The inner one is made of stainless steel $(\mathrm{d}=0.025 \mathrm{~m}, \delta=2.5 \mathrm{~mm})$, the outer one is made of rubber reinforced hose $(\mathrm{d}=0.065 \mathrm{~m})$.

The inclination of the tube was carried out by rotation of two separating discs in the range of $\psi=0 \ldots 90^{\circ}$. Rotation of the experimental section relative to the tube axis by an angle from 0 to $180^{\circ}$ for estimation of heat flux per unit area value along the perimeter was provided.

HGHFS were installed at the prepared places flush with the outside surface of the tube to reduce distortion in condensate flow. Four HGHFS were placed at the same generatrix at the outer surface of the tube. Four thermocouples of T type were installed diametrically opposite to the HGHFSs. 


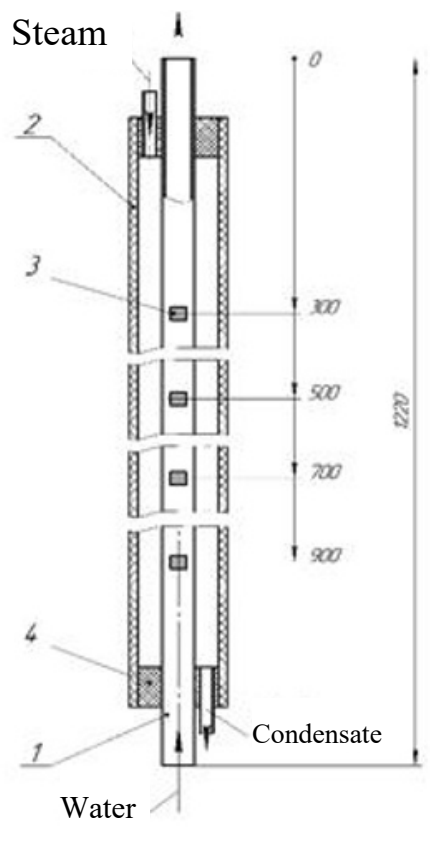

a)

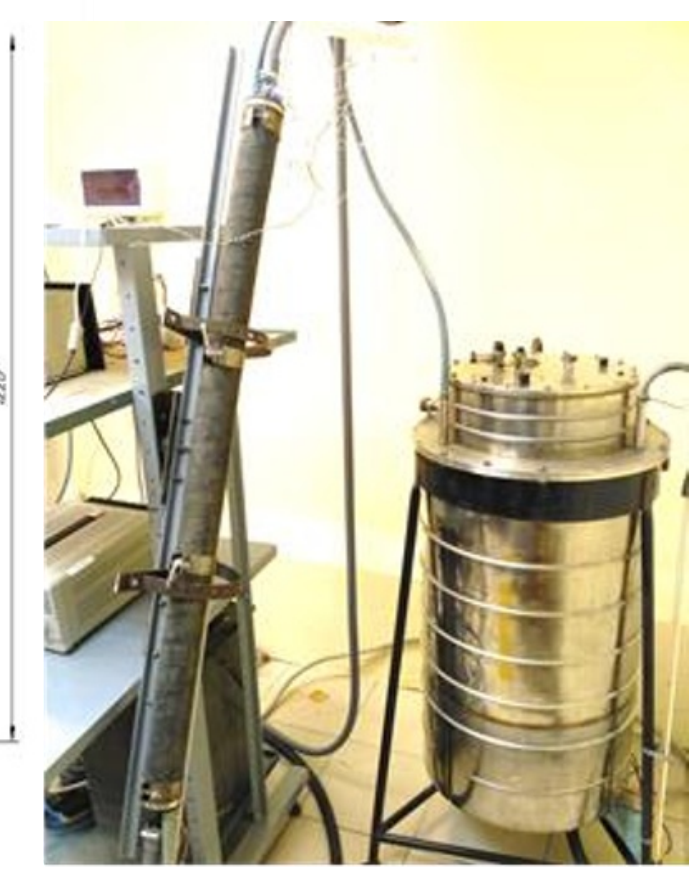

b)

Fig. 3. The experimental setup: (a) sketch, (b) photo. 1 - the tube of stainless steel; 2 - rubber hose; 3 - HGHFS; 4 - rubber plug.

Steam was fed into the annular distance between the tube and the cover from the top. The cooling water was fed into the inner pipe from the bottom.

\section{Results and Discussion}

\subsection{Condensation at the inner surface of the tube}

Pilot experiments were produced when steam was supplied from the upper edge of the tube. The time dependence of heat flux per unit area is shown at figure 4, a.

The following experiments were carried out at steam supply from the bottom. Regime of reflux condensation occurs at the maximal power of the steam generator (figure $4, b$ ). 


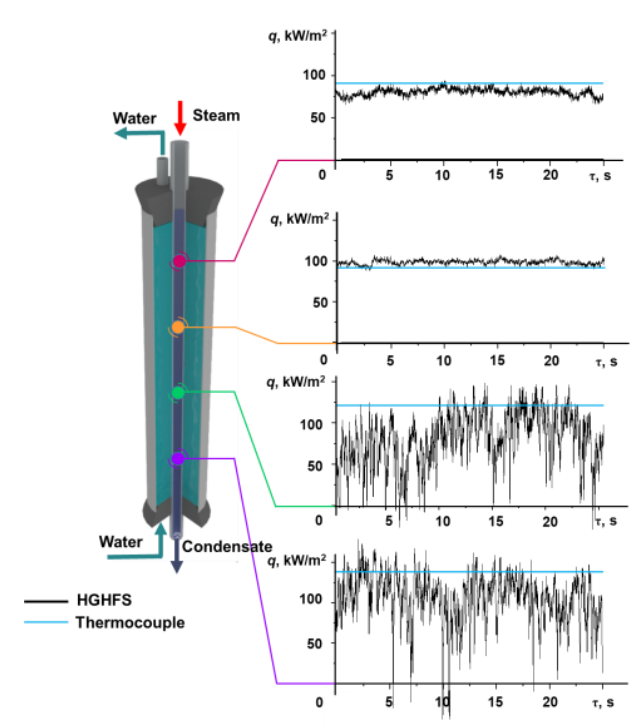

a)

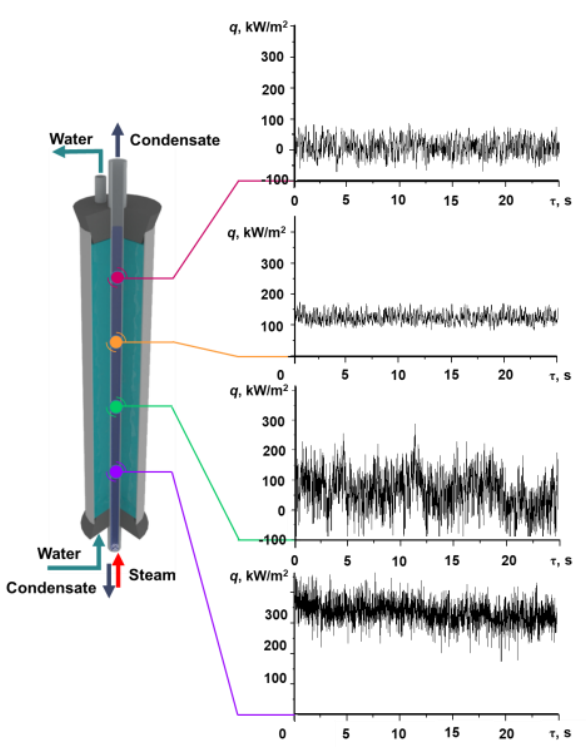

b)

Fig. 4.Heat flux diagram during (a) steam supply from above and (b) steam supply from the bottom. Steam generator power is of $12 \mathrm{~kW}$.

The water plug occurs in the tube when the power of the steam generator was reduced to $7 \mathrm{~kW}$ (figure 5, a). Regime of reflux condensation phenomena becomes after ejection of the plug. The heat power of the setup reduces when the plug regime occurs (figure 5, b).

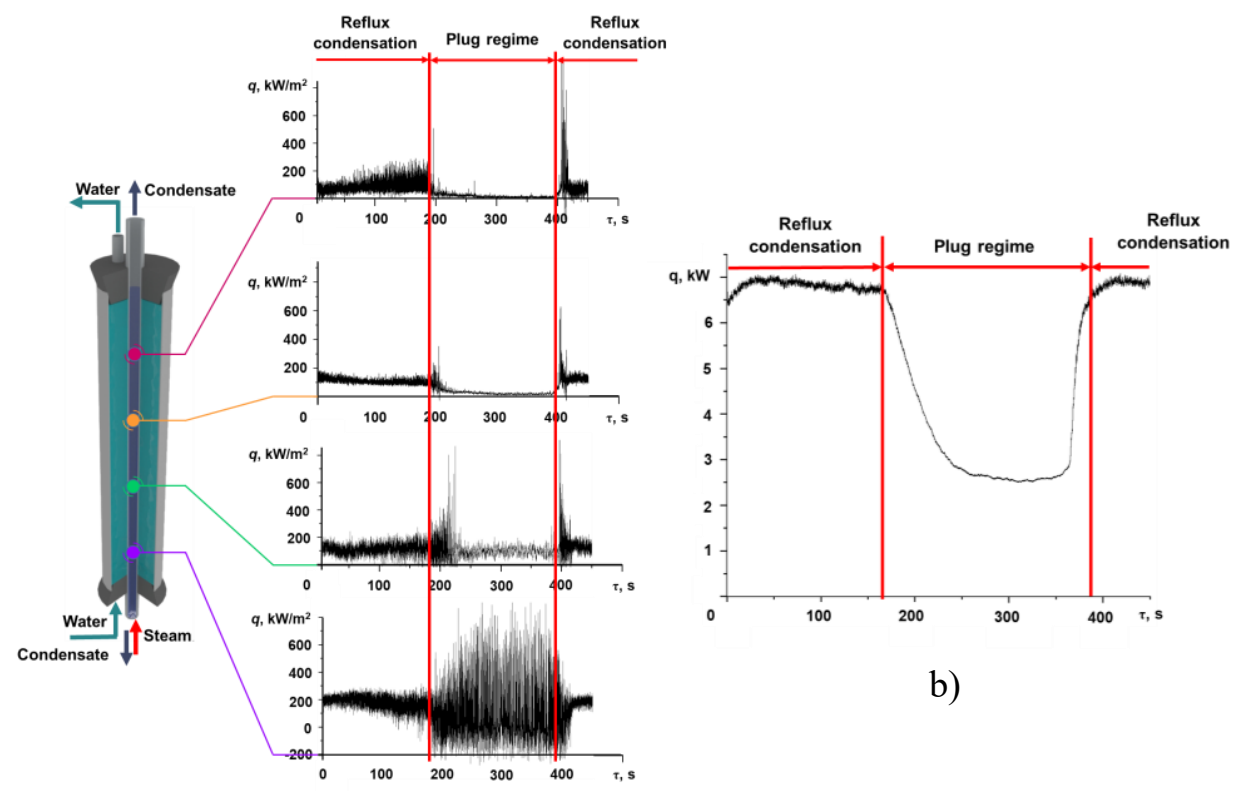

a)

Fig. 5. Heat flux diagram during steam supply from the bottom (a) and heat power of setup (b). Steam generator power is of $7 \mathrm{~kW}$.

While reducing the power of the steam generator up to $5 \mathrm{~kW}$ water plug is not moving upwards but it falls down due to gravity, as it is shown at figure 6 . 


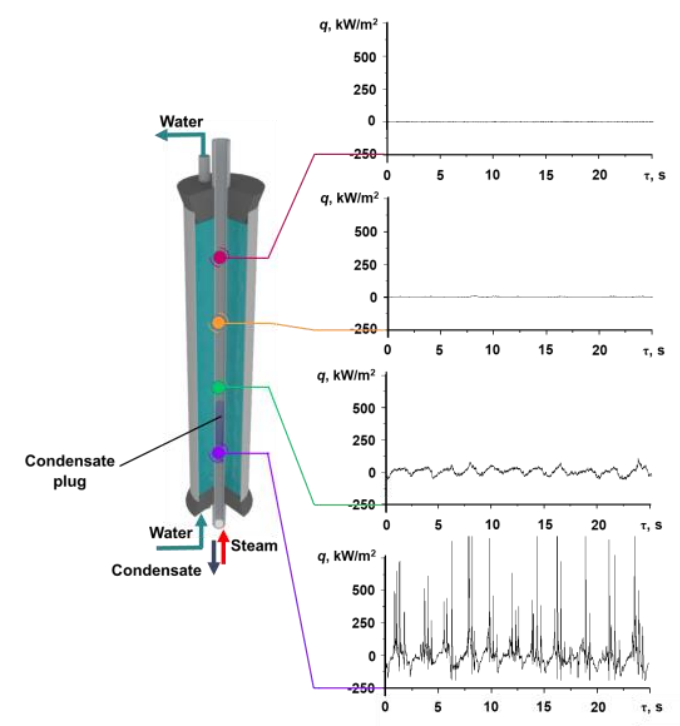

Fig. 6. Heat flux diagram during steam supply from the bottom. Steam generator power is of $5 \mathrm{~kW}$.

The heat flux at the upper HGHFS was equal to zero throughout the entire experiment. The frequency of pulsations of heat flux at the third and fourth HGHFS was about $0.5 \mathrm{~Hz}$.

\subsection{Condensation at the outside surface of the tube}

The applicability of gradient heat flux measurement in study of condensation was tested in experiment for the vertical tube (figure 7).

The signals of the upper HGHFS will not be considered because it is out of order. The heat flux per unit area graph is based on the readings of three other sensors.

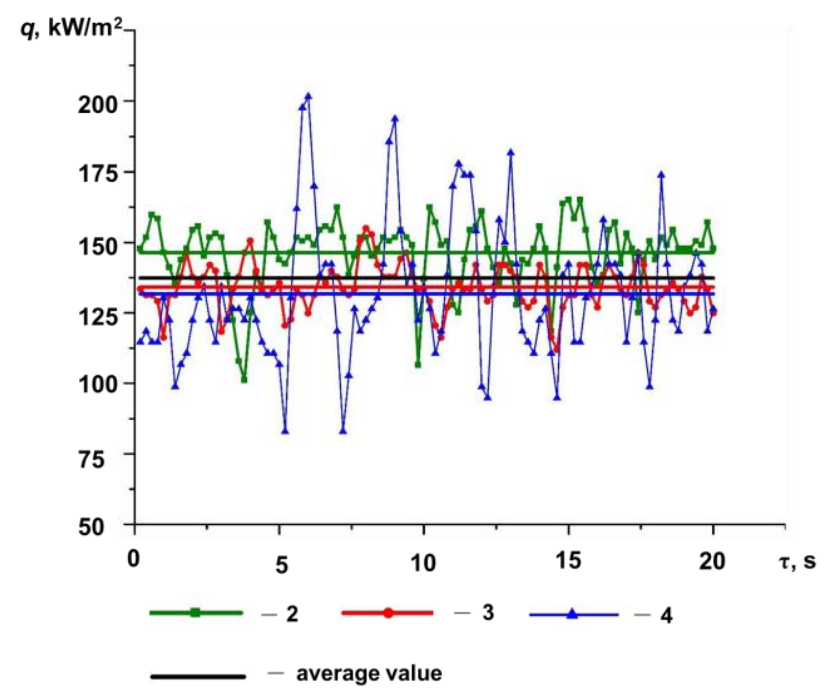

Fig. 7. Heat flux diagram during condensation at the vertical tube.

The heat flux per unit area is represented in dimensionless form. The tube rotates relative to its axis at an angle of $\varphi$, which is counted off from the upper point. The dimensionless heat flux is calculated respectively by the heat flux at the angle of $\varphi=0^{\circ}$ : 


$$
\tilde{q}=\frac{q_{\varphi}}{q_{0}} .
$$

For instance, at figure 8 , a the angular graph of variation in dimensionless heat flux when the tube is tilting at the angle of $30^{\circ}$ to the vertical is shown. Experimental points were obtained by averaging of the readings.

Similar experiments were made in study of heat transfer from the horizontal tube. Figure $8, \mathrm{~b}$ shows the distribution of heat flux along the perimeter of the tube. The average heat flux in all three sections is almost the same.

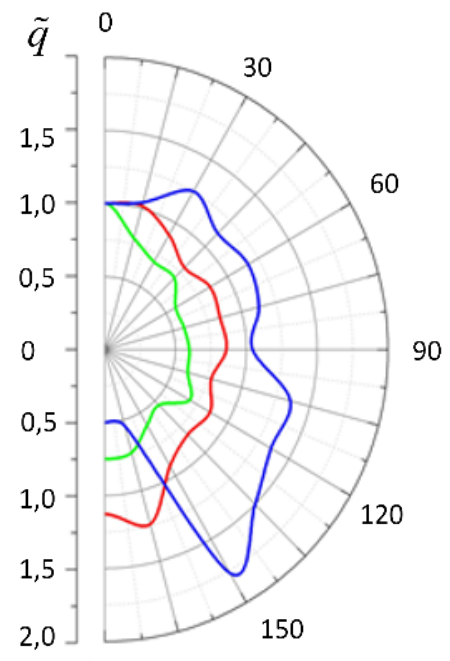

$\phi,^{\circ}$

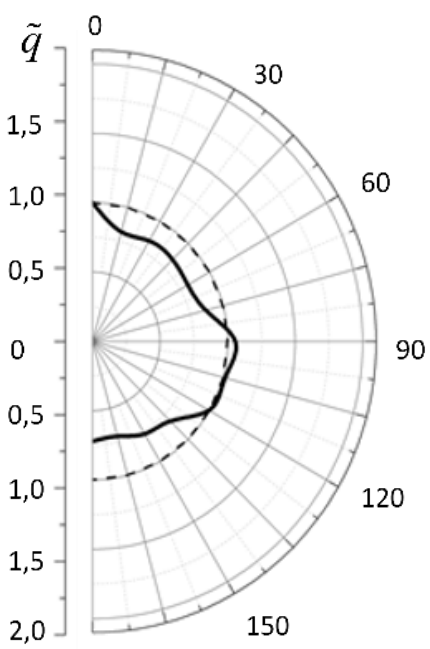

$\phi,^{\circ}$

\section{HGHFS2; HGHFS3; $\quad$ HGHFS4}

Fig. 8. Variation in dimensionless heat flux with respect to angle: (a) the inclination angle of $30^{\circ}$, (b) horizontal tube.

The inclination angle relative to the vertical with the maximal average heat flux along the pipe was found. The heat flux at an inclination angle of $30^{\circ}$ was greater than the average heat flux at the vertical tube by $12.6 \%$ (figure 9 ).

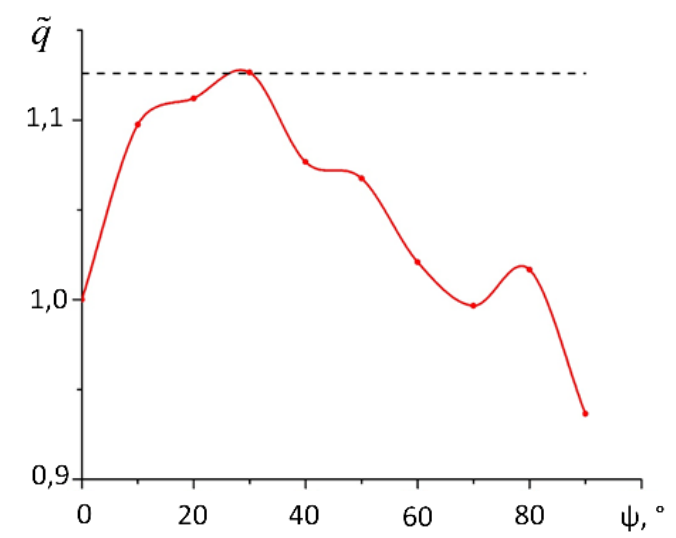

Fig. 9.Variation in dimensionless heat flux with respect to angle $\psi$. 
The average heat flux at the inclination angles of $10^{\circ} \ldots 60^{\circ}$ is higher than at the vertical position.

\section{Conclusions}

The results of our experiments correspond to the classical ideas. The graphs show pulsations of heat flux, which indicates the non-stationarity of heat transfer during condensation. On average, the experimental results differ from the values calculated by the Nusselt formula by $15 \%$, with a standard uncertainty of not more than $10 \%$.

\section{References}

1. $\quad$ W. Nusselt, Z. Ver. Dtsch. Ing. 60 (27), 541-546 (1916)

2. $\quad$ P.L. Kapitsa, Zh. EksperimTeor. Fiz. 18 (3) (1948)

3. P.L. Kapitsa, S.L. Kapitsa, Zh. EksperimTeor. Fiz. 19 (2) (1949)

4. D.A. Labuntsov, Heat power engineering. 2 (1957)

5. W. M. Nozhat, Proc. ASME/JSME Thermal Eng. Conf., Maui, 2, 171-178 (1995).

6. M.Icob, S.Erk, H.Eck, Phis. Zeitschrift,3, (1935).

7. Kyung-Won Lee, HeeCheon NO, In-Cheol Chu, Young Min Moon, Moon-Hyun Chun, International Journal of Heat and Mass Transfer, 49 1813-1819 (2006).

8. Takayoshi Kusunoki, Takahiro Nozue, Kosuke Hayashi, Shigeo Hosokawa, Akio Tomiyama, Michio Murase, Journal of Nuclear Science and Technology

9. P.V. Muratov, R.I. Pashkevich, International Journal of Heat and Mass Transfer 91 494-501 (2015)

10. K. D. Voskresensky, Izvesia USSR, OTN. 7 (1948).

11. K. Hassan, M. Jacob, Trans. ASME 80 (4) (1958).

12. W. Kamminga. Heat and Mass Transfer 23 (9) (1980).

13. Y. G. Lee, Y. J. Jang., D. J. Choi. Inl J. Heat Mass Transfer 104, 1034-1047 (2017).

14. J. X.Zhang, L. Wangb. International Journal of Heat and Mass Transfer 112, 676688 (2017).

15. A. V. Mityakov, S. Z. Sapozhnikov, V. Y. Mityakov, A. A. Snarskii, M. I. Zhenirovsky, J. J. Pyrhönen, Sensors Actuators A Phys. 176, 1-9 (2012).

16. S Z Sapozhnikov et al, J. Phys.: Conf. Ser. 891, 012096 (2017)

17. S. Z. Sapozhnikov, V.Yu. Mityakov, A. V. Mityakov, A. V. Vintsarevich, D. V. Gerasimov, A. V. Pavlov, L. A. Vorobyev, A. V. Larin, Thermal Processes in Engineering 166-170 (2018)

18. A. Mityakov, A. Babich, A. Bashkatov, A. Gusakov, A. Dymkin, E. Zainullina, S. Sapozhnikov, V. Mityakov, V. Seroshtanov, MATEC Web of Conferences. "33rd Siberian Thermophysical Seminar, STS 2017" 02006 (2017)

19. A. Mityakov, V. Mityakov, S. Sapozhnikov, A. Kossolapov, D. Markovich, International Conference on Mechanics - Seventh Polyakhov's Reading C. 7106759 (2015)

20. F. Janasz, D. Suckow, A. Mityakov, M. Furrer, S. Sapozhnikov, V. Mityakov. International youth nuclear congress Burgos, Spain - 6th to 12th July (2014). 